\title{
A Semana da TUberculose de 1937 em CuRitiba: educação para Combater A ENFERMIDADE NA TERRA DOS “BONS ARES"
}

TUberCulosis WeEk 1937 In CURITIBA: EdUCATION TO COMBAT THE DISEASE IN THE LAND OF “GOOD AIR"

\author{
Liane Maria Bertucci* \\ lianebertucci@gmail.com \\ Marinice Sant'Ana de Oliveira** \\ santoli_mar@yahoo.com.br
}

RESUMO: O artigo analisa como se deu a educação para combate da tuberculose na cidade de Curitiba (Paraná) durante a Semana da Tuberculose, realizada em novembro de 1937. O evento organizado por autoridades médico-governamentais mobilizou vários médicos, sendo realizadas palestras, distribuição de folheto educativo e utilização de jornais e da rádio local como difusores de informações. A Revista Médica do Paraná transcreveu algumas das palestras e publicou informações sobre o evento. Não havendo ainda medicamentos específicos para tratamento e cura da tuberculose, as recomendações baseavam-se na importância da higiene (individual e do ambiente), de uma alimentação adequada e uma vida "sem excessos" como formas de prevenção da doença. O tratamento dos tuberculosos apregoado pelos médicos se sustentava quase que exclusivamente no regime higiênicodietético e no isolamento, visto como imprescindível para evitar novos contágios e para aumentar as possibilidades de cura.

PALAVRAS-CHAVE: educação para a saúde; tuberculose; discurso médico-científico.

ABSTRACT: This article analyzes how education was used to combat tuberculosis in the city of Curitiba (Paraná) during Tuberculosis Week in November of 1937. The event was organized by medical and government authorities. Many doctors were involved. Lectures were given, a pamphlet was distributed and newspapers and local radio stations helped to spread information. The Revista Médica do Paraná (Paraná State Medical Journal) transcribed some of the lectures and published information about the event. At the time there was no specific treatment or cure for tuberculosis and the recommendations that were made were based on the importance of hygiene (individual and environmental), an adequate diet and a life "without excess" as ways of preventing the disease. The treatments heralded by doctors

\footnotetext{
* Doutora em História pela Universidade Estadual de Campinas (Unicamp), realizou estágio de Pós-Doutorado na Faculdade de Medicina da Universidade de São Paulo (USP); professora associada de História da Educação e do Programa de Pós-Graduação em Educação na Universidade Federal do Paraná (UFPR).

** Mestre em Educação pela Universidade Federal do Paraná (UFPR).
} 
were almost exclusively based on diet, hygiene and isolation, which was seen as necessary for avoiding contagion and increasing the chances of finding a cure.

KEYWORDS: health education; tuberculosis; medical and scientific discourse.

\section{Introdução}

A definição clássica dos doentes tuberculosos foi feita no século I d. C. por Arete da Capadócia: "febre baixa mas contínua, perda progressiva das forças. Aspecto final de um cadáver vivo com faces rosadas e salientes, olhos brilhantes encerrados nas órbitas" (GUERRAND, 1991, p.188). Definição que resistiu a "passagem da tísica à tuberculose" (FAURE, 2008, p.32) que ocorreu com a elaboração do quadro nosológico da doença por René Laënnec, no início do século XIX. Metáfora da morte passiva, muitas vezes apresentada como tradução do ideal romântico na Era Vitoriana (SONTAG, 1984), a tuberculose continuou a despertar grande temor mesmo depois da identificação do bacilo causador da doença por Robert Koch, em 1882, e dos estudos seguintes que relacionavam salubridade, higiene pessoal e boa constituição física como meios de prevenção e cura da tuberculose. (GUERRAND, 1991; ROSEN, 1994, p.241-246). Nas primeiras décadas do século XX, em tempos de crescimento urbano, do adensamento da ocupação de espaços e do incremento da circulação de indivíduos, o grande número de vítimas da tuberculose aterrorizou as pessoas, inclusive após a introdução da vacina BCG contra a doença ${ }^{1}$.

No Brasil do início dos Novecentos a tuberculose estava entre as moléstias que mais matavam nos grandes centros urbanos, como Rio de Janeiro e São Paulo, cidades onde foram organizadas instituições especialmente voltadas para o combate à doença. Entre elas, o Dispensário criado em 1902 no Rio de Janeiro pela Liga Brasileira Contra a Tuberculose (1900), que durante uma década foi a única instituição especializada no tratamento e profilaxia da enfermidade na cidade (NASCIMENTO, 2005, p.47-65). Em São Paulo, a Liga Paulista Contra a Tuberculose, que existia desde 1899², inaugurou em 1904 o Dispensário Antituberculoso para atendimento de doentes pobres e também estabeleceu um Preventório Infantil na cidade de Bragança Paulista. (BERTOLLI FILHO, 2001, p.60-67). Nos anos seguintes, em algumas partes do Brasil, enfermarias para isolamento e tratamento dos

\footnotetext{
${ }^{1}$ A vacina BCG (Bacilo de Calmette e Guérin) foi desenvolvida nos anos de 1910 por Albert Calmette e Camille Guérin, que comprovaram sua eficácia em 1918 e a apresentaram à Academia Francesa de Medicina em 1924 (NASCIMENTO, 2005, p. 75). A vacina começou a ser utilizada no Brasil nos anos 1930, mas seu uso se intensificou apenas nas décadas seguintes.

${ }^{2}$ Criada em 1899 a Associação Paulista de Sanatórios Populares para Tuberculosos, recebeu em 1903 um novo nome: Liga Paulista Contra a Tuberculose. A entidade teve como presidente o médico Clemente Ferreira desde a fundação no final dos Oitocentos até 1945 (BERTOLLI FILHO, 2001, p.62-63).
} 
tuberculosos e depois alguns hospitais para estes enfermos foram organizados por ações governamentais e de particulares, por vezes em parceria. De acordo com Bertolli Filho, em meados da década de 1930, os sanatórios, voltados especificamente para isolar e tratar tuberculosos, estavam distribuídos desta forma pelo Brasil: 14 sanatórios e hospitaissanatórios em São Paulo; 3 em Minas Gerais; 2 no Rio de Janeiro e 1 no Paraná (BERTOLLI FILHO, 2001, p. 70).

O Sanatório São Sebastião, fundado em 1927 na cidade da Lapa, a cerca de 60 quilômetros de Curitiba, foi a primeira instituição criada no Paraná para isolamento e tratamento especializado de tuberculosos; tinha uma seção destinada aos chamados "pensionistas" que custeavam seu tratamento e outra aos "doentes pobres", mantidos pelo governo estadual (JUK; FERNANDES, 1992, p. 60-63; PARANÁ, 1932-1939, p.48). Como escreveu Perrot, "lugar de tratamento médico, o sanatório foi um campo de experimentação do quarto de longa estada" (PERROT, 2011 p.258).

Em fins da década de 1930, Curitiba contava com um Dispensário Antituberculoso, localizado no Pavilhão Leocádio Correa (organizado em 1934) junto ao Hospital Oswaldo Cruz $^{3}$. Em 1937 este Dispensário, subordinado à Inspetoria da Tuberculose da Diretoria Geral de Saúde Pública do Paraná, estava aparelhado para efetuar diagnóstico clínico, bacteriológico e radiológico e realizava o tratamento de mais de 300 enfermos. No Hospital Oswaldo Cruz existia também uma enfermaria para internamento de tuberculosos, mantida pelo governo paranaense e sob a responsabilidade dos médicos do Dispensário (FERNANDES, [1993?], p.35-38; JUK; FERNANDES, 1992, p.82). A enfermaria realizava o "serviço de vigilância sanitária" contando com enfermeiras visitadoras, figuras centrais nessa modalidade de ação, responsáveis por levar os ensinamentos higiênicos às residências dos doentes, atraindo-os para os consultórios médicos a fim de serem examinados e tratados (Revista Médica do Paraná, maio 1938, p.211). Como escreveu Nascimento, os dispensários teriam como objetivo primordial a profilaxia, mas "estes dispensários acabaram por assumir também ações terapêuticas que caberiam aos hospitais e sanatórios, em função da carência de leitos [...]" (NASCIMENTO 2005, p.75).

Essa organização de uma estrutura antituberculosa na cidade de Curitiba coincidiu com reformas centralizadoras que foram impulsionadas pelo governo Getúlio Vargas durante a gestão Gustavo Capanema (1934-1945) no Ministério da Educação e Saúde Pública, que passou a ser denominado Ministério da Educação e Saúde em 1937. Segundo

\footnotetext{
${ }^{3}$ Fundado em 1928, sob a denominação de Hospital de Isolamento de Curitiba, teve seu nome alterado para Hospital Oswaldo Cruz em 1929. Tal mudança teria ocorrido em razão da expressão 'isolamento’ trazer ao local e aos internos um estigma ainda maior do que aquele que as doenças contagiosas já traziam para seus portadores (FERNANDES, [1993?], p. 35).
} 
Fonseca e Hochman, essas mudanças do final dos anos 1930 tinham como pretensão "[a] construção de aparato governamental nas esferas federal, estadual e municipal em projeto unificado" (FONSECA; HOCHMAN, 1999, p.81). Na área da saúde pública destaque para a criação das Delegacias Federais de Saúde localizadas em oito regiões do território brasileiro, que supervisionavam serviços relacionados à área que eram realizados pelo governo federal ou com sua colaboração ${ }^{4}$, e as ações direcionadas para o combate prioritário às doenças infectocontagiosas, que atingiam grande percentual da população brasileira e não apenas a grupos específicos. Entre essas doenças estava a tuberculose, cujo número de vítimas crescia de maneira exponencial desde a virada para o século XX (HOCHMAN, 2005). Analisando esse processo Fonseca afirmou:

Em torno das concepções de prevenção definiram-se estratégias de ação e prioridades a doenças e regiões, além de especializações profissionais e delimitação de interesses. Associada, em alguns momentos, à noção de higiene ou a práticas de educação em saúde, a ideia de prevenção esteve sempre presente nos debates relativos à saúde pública (FONSECA, 2007, p. 49-50).

Foi nesse contexto e com preocupações evidentemente relacionadas à prevenção da moléstia, que foi realizada em Curitiba a Semana da Tuberculose, entre os dias 7 e 13 de novembro de 1937. Um dia antes do início efetivo das atividades programadas da Semana, um jornal da capital paranaense assim resumia o principal objetivo do evento: "difundir ensinamentos ao povo acerca do implacável mal dizimador dos povos [...]" (Diário da Tarde, 6 nov.1937, p.1).

\section{A Semana da Tuberculose de 1937 em Curitiba}

Em 1937 Curitiba contava com 119.625 habitantes e, segundo o doutor Emílio Leão de Mattos Sounis, professor da Faculdade de Medicina do Paraná, a porcentagem de mortos pela tuberculose naquele ano somou $8 \%$ do total dos 1634 óbitos que ocorreram no

\footnotetext{
${ }^{4}$ As delegacias encontravam-se assim organizadas: (1) Distrito Federal e Estado do Rio de Janeiro; (2) Território do Acre e Estados do Amazonas e Pará; (3) Estados do Maranhão, Piauí e Ceará; (4) Estados do Rio Grande do Norte, Paraíba, Pernambuco e Alagoas; (5) Estados de Sergipe, Bahia e Espírito Santo; (6) Estados de São Paulo e Mato Grosso; (7) Estados do Paraná, Santa Catarina e Rio Grande do Sul e (8) Estados de Minas e Goiás. Suas sedes estavam localizadas nas seguintes cidades: Rio de Janeiro, Belém, Fortaleza, Recife, Salvador, São Paulo, Porto Alegre e Belo Horizonte (HOCHMAN, 2005).
} 
município. O estudo de Sounis, realizado em 1940, indicava um aumento relativamente regular de vítimas fatais da moléstia na localidade, conforme mostra o quadro abaixo:

\begin{tabular}{|c|c|c|c|c|c|}
\hline Anos & População & $\begin{array}{l}\text { Número de } \\
\text { óbitos por } \\
\text { tuberculose }\end{array}$ & $\begin{array}{c}\text { Obituário } \\
\text { Geral }\end{array}$ & $\begin{array}{l}\text { Porcentagem } \\
\text { sobre }\end{array}$ & $\begin{array}{l}\text { Coeficientes em } \\
100 \text { mil habitantes }\end{array}$ \\
\hline 1930 & 103.000 & 77 & 1502 & 5,1 & 74,7 \\
\hline 1931 & 105.000 & 81 & 1382 & 5,8 & 77,1 \\
\hline 1932 & 108.000 & 83 & 1371 & 6,0 & 76,8 \\
\hline 1933 & 111.000 & 83 & 1439 & 5,7 & 74,7 \\
\hline 1934 & 114.000 & 102 & 1572 & 6,4 & 89,4 \\
\hline 1935 & 116.000 & 117 & 1527 & 7,6 & 100,8 \\
\hline 1936 & 117.000 & 116 & 1792 & 6,4 & 98,7 \\
\hline 1937 & 119.625 & 132 & 1634 & 8,0 & 110,3 \\
\hline
\end{tabular}

FONTE: SOUNIS, 1940, p.39

Nos anos 1930 esse aumento, mesmo oscilante, deveria assustar médicos e vários outros moradores da capital paranaense que eram informados sobre o número de tuberculosos na cidade, pois Curitiba, com seu clima ameno, era considerada uma das capitais de estados brasileiros mais saudáveis e durante anos o coeficiente de mortes pela doença ficou abaixo de 100 por 100 mil habitantes (SOUNIS, 1940, p.38), limite considerado aceitável pelas autoridades médicas. Nesse período, avaliação realizada pelo médico João de Barros Barreto ${ }^{5}$, a partir de dados dos anos 1931 a 1935, continuava a apontar Curitiba e

\footnotetext{
${ }^{5} \mathrm{O}$ médico João de Barros Barreto teve papel decisivo nas reformas implantadas por Gustavo Capanema na área da saúde do Ministério da Educação e Saúde, atuando como diretor do Departamento Nacional de Saúde de 1937
} 
as cidades de Teresina e Cuiabá como as capitais com "mortalidade moderada" pela tuberculose, isto é, dentro de um limite aceitável. Era preciso manter esta colocação (Revista Médica do Paraná, fev.1938, p. 66).

Assim, no final da década de 1930, o crescente número de mortes pela doença era um alerta para os curitibanos, pois apesar das benesses de seus "bons ares", que foi argumento até para a instalação da capital da província (depois estado) em Curitiba em 1853 (BERTUCCI, 2011), era necessário redobrar os esforços para barrar a tuberculose. O clima ameno não garantia imunidade contra a doença, o que inclusive era possível constatar com a simples observação da presença de Teresina e Cuiabá (cidades de clima muito diverso daquele da capital paranaense) no grupo de "mortalidade moderada" pela tuberculose. Possíveis explicações que justificassem o maior ou menor número de óbitos pela moléstia necessitavam, portanto, da combinação de dados diversificados que extrapolavam o clima local, como por exemplo, densidade demográfica, nível de urbanização e industrialização e estrutura de prevenção, diagnóstico e tratamento para esta enfermidade.

Essa perspectiva ampla, que poderia ajudar a compreender o aumento do número de vítimas fatais da doença em Curitiba nos anos 1930, também, pode ter concorrido para mobilizar médicos e leigos na realização da Semana da Tuberculose em 1937; uma atividade preventiva que estava em sintonia com as novas diretrizes nacionais para a saúde, que foi coordenada por órgãos do governo do Estado e aconteceu notadamente na capital paranaense.

Em novembro de 1937, o conturbado momento político brasileiro, em meio ao golpe do Estado Novo, parece não ter prejudicado a realização daquilo que estava previsto para a Semana da Tuberculose, organizada pelos doutores Eduardo Virmond Lima, Diretor Geral da Saúde Pública do Paraná; Ary Taborda, Inspetor de Profilaxia Geral, e Milton Munhoz, Inspetor da Tuberculose (Revista Médica do Paraná, nov.-dez. 1937, p.492). A Semana foi oficialmente inaugurada na tarde do dia 6 de novembro no Teatro Avenida (o melhor espaço artístico de Curitiba na época) e a programação do evento, de 7 a 13 de novembro, foi publicada diariamente pela imprensa curitibana; uma tentativa evidente de difundir as atividades que aconteceram em múltiplos espaços da cidade, com palestras médicas transmitidas pela rádio local, algumas delas também publicadas, parcial ou totalmente, em jornais de Curitiba e posteriormente na Revista Médica do Paraná, durante

a 1939 e de 1941 a 1945. Era frequentemente lembrado por médicos paranaenses através de artigos da Revista Médica do Paraná, que muitas vezes evidenciavam sua produção como sanitarista e sua relação com o Paraná, pois havia atuado no estado no início dos anos 1920 como chefe do Serviço de Profilaxia Rural do Paraná, criado em 1918. 
o ano de 1938. Outra ação realizada durante o evento foi a oferta de folheto educativo ${ }^{6} \mathrm{em}$ locais com grande circulação de pessoas, como escolas, quartéis, fábricas, estações de bondes e de estrada de ferro e cinemas. Mesmo centrando suas atividades na capital do Estado, a Semana da Tuberculose teve a pretensão de atingir a população de outras localidades paranaenses com a realização de palestras e "farta distribuição" do folheto educativo por 38 Delegacias de Higiene do interior ${ }^{7}$, conforme informou edição da Revista Médica do Paraná que circulou no final de 1937; edição que também trazia o seguinte comentário sobre o evento:

[...] Nos cinemas, foram exibidos diapositivos com conselhos, e uma película sobre o armamento da Saúde Publica do Paraná.

Também foi realizado um Concurso de Cartazes Educativos.

Duas faixas de pano (duplas), com legendas, foram afixadas [em Curitiba] na Rua Quinze e na Praça Tiradentes (em frente da estação de bondes).

O grande acontecimento da Semana foi a criação da Liga Paranaense Contra a Tuberculose, em beneficio da qual foram realizados inúmeros festivais beneficentes (Revista Médica do Paraná, nov.-dez.1937, p.492493).

A estratégia pedagógica de realização de palestras e distribuição de folhetos informativos, com o objetivo de atingir o maior número possível de pessoas, era uma prática realizada pelas autoridades médicas do Paraná em outros períodos, contra outras doenças também. Dois exemplos foram: a campanha pelo saneamento rural desenvolvida no Estado entre 1918 e 1930 (KUMMER, 2007, p.91) e a disseminação de ensinamentos preventivos às doenças venéreas, que aconteceu nos anos 1920, quando palestras eram realizadas e folhetos distribuídos em estabelecimentos coletivos de Curitiba (STERN, 2003, p.126). 0

\footnotetext{
${ }^{6}$ Considerando informações reproduzidas em jornais diários de Curitiba e na Revista Médica do Paraná é possível supor que foram distribuídos vários exemplares de um mesmo folheto e não de diferentes folhetos. Não foi encontro exemplar (ou imagem) deste folheto.

${ }^{7}$ Foram localizadas informações sobre atividades durante a Semana da Tuberculose nas cidades de Antonina, Araucária, Paranaguá e Serro Azul (Revista Médica do Paraná, nov.- dez.1937, p.492-493; abr. 1938, p.165175). No Paraná do final dos anos 1930, a tuberculose, considerada, por excelência, uma doença dos maiores centros urbanos, também mobilizava a atenção dos médicos sobre os moradores do meio rural e de pequenas localidades, notadamente de áreas próximas de locais para tratamento de tuberculosos (como a Lapa) ou de clima considerado propício para a cura destes enfermos, como Araucária, pois seria em razão da atração destes lugares que a moléstia, via migrantes tuberculosos, estaria se disseminando em áreas rurais (Revista Médica do Paraná, abr.1938, p.169-170). Entretanto, de acordo com o estudo de Juk e Fernandes sobre o Paraná, já em 1927, primeiro ano de funcionamento do Sanatório São Sebastião, na Lapa, os lavradores junto com os operários braçais e as domésticas formavam um grupo que somava cerca de dois terços do total de internados (JUK; FERNANDES, 1992, p. 62).
} 
diferencial da ação educacional contra tuberculose em fins dos anos de 1930 foi utilizar um veículo de comunicação recente: o rádio, que nas décadas posteriores viria a ser um dos mais importantes meios de comunicação no país ${ }^{8}$.

O rádio e o jornal tiveram significativo destaque na empreitada educativa durante a Semana da Tuberculose de 1937. A estação Rádio Clube P.R.B.2 de Curitiba ${ }^{9}$ transmitia diariamente as palestras sobre o tema, sendo que algumas dessas depois ganhavam as páginas dos jornais. Além disso, os jornais curitibanos publicavam artigos sobre a repercussão do evento, textos com conselhos educativos e comentários sobre ações médicas e beneficentes que visavam o combate à doença.

A primeira dessas palestras foi a realizada na sessão inaugural da Semana pelo médico Milton Munhoz, um dos organizadores do evento, que além de Inspetor da Tuberculose era catedrático de Higiene da Faculdade de Medina do Paraná e editor da Revista Médica do Paraná. Durante sua fala Munhoz colocou a saúde como fator de progresso e da felicidade humana, apontando a doença como um malefício que não estava restrito ao indivíduo, mas repercutia em prejuízos à família e a nação, pois a pessoa doente deixava de ser produtiva e gerava um ônus social, seria como um peso na sociedade (Revista Médica do Paraná, maio 1938, p.207). Essas palavras do médico estavam em consonância com o discurso sanitarista, que desde os anos de 1910 apontava a doença como fator de atraso nacional e destacava a saúde como condição para o desenvolvimento nacional (LIMA; HOCHMAN, 1996; CASTRO SANTOS; FARIA, 2003, p.37-47).

No mesmo discurso Milton Munhoz destacava o papel da medicina e da higiene como formas de prevenir enfermidades e assim concorrer para a saúde individual e da coletividade. Quanto à tuberculose, era apontada como uma doença social, inerente à civilização e que nas modernas cidades vitimava principalmente os mais pobres:

"[...] a promiscuidade da vida citadina, a fragilidade de organismos mal alimentados, a fadiga do trabalho estafante que a civilização impõe e o progresso reclama, as insuficiências higiênicas das habitações e porque

\footnotetext{
${ }^{8}$ A Rádio Sociedade do Rio de Janeiro, considerada a primeira rádio do Brasil, foi fundada em 20 de abril de 1923, contando entre seus fundadores com Edgard Roquette-Pinto, defensor da utilização do rádio como instrumento educativo (MOREIRA; MASSARANI; ARANHA, 2008). Nos anos de 1930, especialmente a partir do Estado Novo, o rádio também esteve a serviço da propagação do ideário varguista e foi utilizado para programas relacionados à educação para a saúde que faziam parte da política governamental de saúde pública (GONÇALVES, 2011).

${ }^{9}$ A Rádio Clube P.R.B.2, também denominada Rádio Clube Paranaense, foi a primeira rádio do Paraná, fundada oficialmente em 27 de junho de 1924 (HOEMER JUNIOR, 2005, p.43-44).
} 
contra ela, contra seu domínio envolvente, pouco ou nenhuma resistência tem sido oposta" (Revista Médica do Paraná, maio1938, p.207).

Concepção semelhante pode ser percebida em vários artigos publicados pela imprensa curitibana, entre eles um texto de 1937, assinado por Juan de Aviz:

A tuberculose é por excelência a moléstia que vitima a pobreza, encontrando-a parca de bom ar e de sadia alimentação nos grandes centros. Preferencialmente a miséria é a mais sinistra aliada da enfermidade. Cumpre, portanto, preservar a existência anti-higiênica dos cortiços e batalhar pelo levantamento do nível alimentar da grande massa encaminhando-lhe um regime resistente às investidas fáceis do bacilo de Koch (Diário da Tarde, 10 nov. 1937, p.2).

Destacando o que entendia como as principais causas do desenvolvimento da tuberculose, o autor do artigo sinalizava soluções: higiene e boa alimentação; mas não arriscava uma sugestão de como efetivá-las. Juan de Aviz, provavelmente um pseudônimo, poderia ser um médico ou um leigo bem educado (segundo a perspectiva dos doutores), entretanto, independente do grau de conhecimentos médico-científicos do autor, a linguagem utilizada no texto (além do veículo de comunicação em que o artigo foi publicado) indicava que o objetivo de quem escreveu era fazer circular considerações sobre a tuberculose entre grande parcela da população. Um fato chama, particularmente, a atenção: o uso do termo da ciência médica "bacilo de Koch". A utilização do termo, mesmo sem maiores explicações (o que seria um bacilo?), em meio a considerações bem mais difundidas e que eram de fácil entendimento, como as que relacionavam higiene com saúde, colaborariam para uma aproximação do saber médico, e do médico, com a população em geral, mesmo que, como afirmou Bertucci-Martins (2005), esse tipo de citação pouco esclarecesse as pessoas sobre a saúde e as doenças.

Assim, nas considerações de Munhoz e de Aviz, a tuberculose era apontada como uma doença ligada prioritariamente à pobreza, mas era evidente que ela circulava entre diferentes grupos sociais. A diferença, provavelmente, estava nas melhores condições de vida dos mais abastados, o que já servia como prevenção à enfermidade, e na possibilidade que tinham de, quando tuberculosos, receber uma boa alimentação e ser isolados em suas casas higiênicas ou mandados para sanatórios bem equipados.

Não havendo ainda medicação específica para o tratamento efetivo da tuberculose, com a vacina em processo de difusão, o discurso médico dava ênfase na profilaxia para que 
ocorresse a diminuição dos casos em Curitiba. A prevenção teria como base a higiene, muito focada na responsabilidade individual.

Educar muitas pessoas individualmente era tarefa impossível, entretanto, o folheto distribuído fartamente durante a Semana da Tuberculose talvez pudesse ser lido, guardado e até divulgado por vários moradores da cidade. O conteúdo deste impresso foi transcrito pelos jornais Diário da Tarde e Correio do Paraná e é possível perceber que o folheto foi elaborado de forma a impactar, captar a atenção do leitor e conseguir sua adesão às práticas propostas. O texto começava informando o número de óbitos causados pela tuberculose no Brasil em geral, e no Paraná em particular: no país existiriam 800.000 tuberculosos e a cada 5 minutos morria um destes doentes; no Paraná existiriam cerca de 10.000 pessoas tuberculosas e em Curitiba mais de 800 indivíduos estavam acometidos pela doença. A seguir, sinalizando a possibilidade de reverter essa triste situação, a tuberculose era apresentada como uma doença curável, desde que diagnosticada e tratada no começo, quando o organismo ainda apresentava possibilidade de resistência para vencê-la. Por isso todo tuberculoso deveria saber qual a sua doença desde o princípio para tratar-se, curar-se e, também, observar as medidas de higiene indispensáveis para evitar o contágio de seus semelhantes. Para que isso fosse possível, vários sintomas eram descritos e se detectados a pessoa deveria procurar imediatamente a saúde pública (Diário da Tarde, 8 nov.1937, p.2; Correio do Paraná,13 nov.1937, p.3. Confira também Revista Médica do Paraná, abr.1938, p.172-174).

Iniciar um texto com impacto gerado por números (algo aparentemente neutro, verdadeiro) foi estratégia utilizada por alguns médicos durante as palestras da Semana da Tuberculose, que assim criavam um cenário de perigo constante e de necessidade de cuidado, já que a ocorrência da tuberculose era posta como certeza de tristeza e desgraça, um prenúncio de morte, caso o doente não seguisse as prescrições médicas. E essas prescrições foram difundidas repetidamente, em jornais ou palestras, durante a Semana, expostas de maneira a serem facilmente entendidas pelo público. O jornal Correio do Paraná publicou:

\section{PARA EVITAR A TUBERCULOSE}

Durma de janelas abertas.

Trabalhe em lugar arejado e iluminado.

Viva o mais possível ao ar livre.

Alimente-se bem, a horas certas, mastigue bem e coma devagar.

Não toque nos alimentos sem ter as mãos bem lavadas com água e sabão. Observe o maior asseio na sua habitação e do seu corpo. 
Combata as moscas como grandes inimigos.

Durma pelo menos sete horas por dia.

Evite o álcool e os excessos de qualquer natureza.

Evite a companhia das pessoas que tossem [...]

(Correio do Paraná, 13 nov.1937, p.3).

E os conselhos continuavam em palestras, como transcreveu meses depois a Revista Médica do Paraná:

\section{A TUBERCULOSE É CURAVEL E EVITAVEL}

[...] Para isso é preciso que todos saibam que os seguintes sintomas são suspeitos de tuberculose:

- ligeira febre que aparece, quase sempre, á tarde ou depois de esforço físico;

- Cansaço inexplicável, insônias ou sono que não repousa e sensação de fadiga ao despertar;

- emagrecimento, perturbações de digestão, dores de cabeça, sem causa explicável;

- escarros de sangue, pontadas no peito e nas costas, mesmo sem tosse;

- gripes e resfriados repetidos, principalmente sem defluxo;

- gânglios (ínguas), palidez, emagrecimento e tristeza, principalmente nas crianças;

- falta de apetite, dores nas juntas, bronquites crónicas;

- falta de desenvolvimento das crianças de pouca idade, principalmente quando vivem em companhia de pessoas tuberculosas;

- convalescença prolongada do tifo, gripes e outras moléstias;

- tosse que dura mais de quinze dias e que não cede aos remédios comuns;

- falta de ar, suores noturnos, rouquidão, tosse que provoca vômitos.

(Revista Médica do Paraná, abr.1938, p.173).

A orientação dada era que ao sentir a presença de qualquer desses sintomas o indivíduo consultasse sem demora o seu médico ou o Dispensário Antituberculoso de Curitiba, para a realização do diagnóstico correto e, se por acaso tivessem contraído tuberculose, para receber orientação adequada para seu tratamento. A esperança que a tuberculose poderia ser curada, desde que diagnosticada e tratada desde seu princípio, estava ligada a supervisão e controle da ciência médica.

Como lembrava o médico Milton Munhoz, no discurso da cerimônia de abertura da Semana da Tuberculose, a doença poderia ser adquirida em diversos ambientes, como fábricas, escolas, quartéis, cafés, e de diferentes formas, mas, a primeira causa de difusão da doença seria o contágio inter-humano, tendo como principal transmissora a família 
porque facilitava e mantinha contatos repetidos com os doentes. Munhoz apresentava afirmações sobre má alimentação, fadiga no trabalho, hábitos viciosos (como uso bebidas alcoólicas) ou sequelas de outras doenças, como fatores que enfraqueciam o organismo humano e facilitavam a ocorrência da tuberculose, mas eram as práticas higiênicas aquelas consideradas fundamentais tanto para preservar da doença quanto para impedir sua proliferação. O tuberculoso sem hábitos higiênicos que permanecia no meio familiar foi apontado pelo médico como a principal causa da disseminação da tuberculose. 0 médico também destacou a presença dos empregados domésticos como possibilidade de risco, de fora para dentro, no ambiente familiar (Revista Médica do Paraná, jun.1938, p. 296-297). O medo do outro, comum em situações que envolviam doenças, notadamente as epidêmicas, neste caso era o medo daqueles que pertenciam a um grupo específico de trabalhadores, 0 dos empregados domésticos (cf. BERTUCCl, 2009, p.462-467) ${ }^{10}$.

Reiterando as considerações de Milton Munhoz, no dia 12 de novembro o doutor José Pereira de Macedo, professor de Anatomia da Faculdade de Medicina do Paraná e exDiretor da Inspeção Médica Escolar paranaense, proferiu uma palestra pela Rádio Clube P.R.B. 2 exaltando os benefícios generalizados da higiene para o combate à tuberculose, assinalando a responsabilidade de cada um pela própria saúde e pela saúde de todos. 0 médico concluiu:

[...] pode descer a Zero [o número de tuberculosos] numa aglomeração em que cada indivíduo se disponha a cooperar com a Saúde Publica na pratica de elementares preceitos de higiene que garantindo a sua própria integridade física repercute beneficamente sobre a coletividade (Revista Médica do Paraná, fev.1938, p. 85-86).

Mas, daquilo que circulou durante a Semana da Tuberculose, foi possível constatar que a maior ênfase foram os cuidados que se deveriam ter com as crianças, pois elas teriam maior facilidade de contrair a doença. Insistentemente pedia-se o afastamento dessa parcela da população dos lares tuberculosos e a construção de um Preventório na cidade de Castro, a cerca de 150 quilômetros da capital paranaense, vinha ao encontro dessa postura vigente no período ${ }^{11}$.

\footnotetext{
${ }^{10}$ Em abril de 1932, lei federal instituiu a carteira de saúde, documento que obrigava os trabalhadores a fazerem exames, entre eles a radiografia do pulmão, para obterem emprego (BERTOLLI FILHO, 2001, p.75). O alcance de tal medida entre os trabalhadores domésticos deve ter sido ínfimo.

${ }^{11}$ O Preventório de Castro, com capacidade para 100 leitos, estava situado fora do perímetro urbano; no local, segundo a Revista Médica do Paraná de 1938, as crianças antes expostas ao contágio no meio familiar seriam submetidas, "[...] em regime de internato, a uma higiene especial, composta por uma alimentação conveniente,
} 
No jornal Correio do Paraná, em coluna intitulada Seção da Mãezinha, assinada pelo médico Orlando Sprenger Lôbo, a tuberculose era colocada como responsável por ceifar a vida de considerável número de crianças todos os anos. As mais atingidas seriam aquelas oriundas das classes menos favorecidas e a explicação para tal fato estaria na repetida argumentação: "[a] falta de higiene dos cortiços e a alimentação deficiente das camadas pobres" (Correio do Paraná, 10 nov.1937, p.7). Os conselhos para que a mortalidade de crianças causadas pela tuberculose retraísse não eram tão diversos daqueles dados ao público adulto.

[...] Não permitir que uma criança conviva com pais, parentes ou criados tuberculosos. Proporcionar aos filhos um saudável hábito de vida, com alimentação racional, bastante ar puro e muito sol, que é a mais econômica, acessível e sempre eficiente arma antituberculosa. E, sobretudo, levar as crianças, periodicamente, a um completo e rigoroso exame médico (Correio do Paraná, 10 nov.1937, p. 7).

Nessa perspectiva de cuidado com a criança o professor primário foi alvo primordial de palestras, como a realizada na Escola Normal de Curitiba durante a Semana da Tuberculose pelo médico Antenor Pamphilo dos Santos, professor de Fisiologia da Faculdade de Medicina do Paraná, que exaltava a ação de normalistas para a luta contra a tuberculose:

[...] Do vosso contato com a criança, nesse período escolar, muito espera a Higiene, porque nessa fase maleável das aptidões infantis podeis incutir hábitos sadios que sobremodo auxiliarão aqueles porventura já recebidos nos lares.

As crianças no meio escolar, onde se encontram elementos com e sem hábitos higiênicos, devem estar sob rigoroso controle das [os] educadoras[es]. Se precipuamente vos cabe educa-las no conhecimento das letras em suas relações com coisas e fatos, não devereis abdicar de outras credenciais implícitas no plano nacional de educação e entre as quais está a competência de apreciar as falhas de educação higiênica das crianças, este livro aberto para vossa leitura quotidiana, corrigindo-as por exemplos, instruções gerais e outros meios suaves ao alcance da compreensão peculiar á idade.

É para contar com vosso empenho valioso na proteção à saúde, este legado divino que devemos zelar para o bem particular e para o bem da Sociedade, que vos dirigimos estas palavras como um apelo em nome das gerações

arejamento contínuo associado a repouso, instrução e exercício físico, dosados pela colaboração de um médico e um pedagogo" (Revista Médica do Paraná, maio 1938, p.211). O Preventório foi concluído em 1940. 
futuras a quem não temos o direito de legar dores e sofrimentos, para que sejais mais um esteio vigoroso e útil na luta contra a tuberculose.

O legado mórbido ás gerações vindouras é um duplo atentado: contra a atualidade e contra o futuro.

A criança de hoje é o adulto de amanhã; da morbidade de agora será ela a portadora se nos mantivermos no comodismo da indiferença que nos conduzirá fatalmente á decadência, ao fracasso da eugenia, já que se anula o dinamismo da unidade biológica da raça, matando, aniquilando na criança a sua inconsciente aspiração de ser sadia, bela e forte (Revista Médica do Paraná, jun.1938, p.299).

Os professores, depois de bem instruídos e cientes de sua responsabilidade com a sociedade, seriam efetivos arautos da ciência médica nas escolas, disseminando diariamente entre seus alunos, que eram pequenos seres em formação, os ideais de higiene para a prevenção da tuberculose e outras doenças.

As palavras do médico na Escola Normal também evidenciavam aspectos que permeavam as discussões sobre eugenia no Brasil e aventavam que as condições do meio ambiente teriam repercussão sobre o patrimônio hereditário, ou seja, miséria e doença comprometeriam não apenas as condições físicas e mentais das pessoas por elas acometidas, mas também a sua prole ${ }^{12}$. A educação higiênica individual, a boa alimentação e o saneamento, fundamentais para o combate à tuberculose, seriam também medidas de caráter eugênico.

A educação, tendo como norte a higiene, para a formação de um povo saudável e a construção de um país grandioso, ideal presente no discurso sanitarista há cerca de duas décadas, continuava sendo evocada na Semana da Tuberculose de 1937. Conforme escreveu Fonseca, "a bandeira do saneamento foi incorporada e reelaborada no projeto políticoideológico [varguista]" (2007, p.29). Dentro desse cenário, o Paraná, segundo palavras de seus médicos, não poupava esforços para participar ativamente da construção do tão almejado futuro.

O major médico Ezequiel Antunes de Oliveira afirmava:

[Tuberculose], a importância da defesa contra o seu contágio, baseada no exercício de uma instrução individual e coletiva, fazendo valerem e

\footnotetext{
${ }^{12}$ Entre as várias obras que abordam diferentes facetas dos debates sobre eugenia no Brasil nas primeiras décadas do século XX, veja, além dos estudos de Marques (1994) Mota (2003) e Stepan (2004), os artigos reunidos no livro Eugenia e história, organizado por Mota e Marinho (2013).
} 
aproveitarem as recomendações benéficas da profilaxia, as quais seguidas, não desdenhadas e nem olvidadas, contribuirão patrioticamente para a saúde e prosperidade do nosso amado e futuroso Brasil (Revista Médica do Paraná, abr.1938, p.175).

O doutor Milton Munhoz dizia:

Formando na vanguarda das legitimas aspirações nacionais, o Paraná já traçou diretrizes seguras de boa brasilidade e procura contribuir para a grandeza da pátria tornando sadio seu povo e salubre seu solo (Revista Médica do Paraná, maio 1938, p.207) ${ }^{13}$.

Assim, o conteúdo das práticas educativas contra a tuberculose propostas na Semana da Tuberculose em 1937 não pode ser desvinculado de aspectos defendidos pelo movimento sanitarista e de algumas características da eugenia no Brasil. Um conteúdo educativo que estava intimamente conectado a um ideário nacionalista que incorporou novos elementos durante o governo Vargas e continuou a advogar que a melhoria das condições de saúde da população brasileira era um fator de desenvolvimento do país, pois uma população saudável e produtiva era imprescindível para o Brasil ocupar um lugar entre as grandes nações.

\section{CONSIDERAÇÕES FINAIS}

Mas, qual a repercussão da Semana da Tuberculose de 1937 entre os curitibanos? Difícil avaliar, entretanto comentário publicado no jornal Diário da Tarde, durante a realização do evento afirmava:

Continua a Semana da Tuberculose com o entusiasmo com que foi iniciada. $\mathrm{E}$ os seus resultados vão se fazendo sentir. Toda gente, mesmo as crianças, comenta o texto dos folhetos distribuídos, as causas, os sintomas, o perigo de contagio, do implacável mal (Diário da Tarde, 09 nov. 1937, p.5).

\footnotetext{
${ }^{13}$ Expressões como "patriótica realização", “patriótica campanha”, presentes em textos do jornal Gazeta do Povo, referindo-se à Semana da Tuberculose, também demonstravam a estreita relação que existia naquele momento entre a educação para a saúde do povo brasileiro e a possibilidade de realização dos ideais de uma grande nação. (cf. Gazeta do Povo, nov. 1937).
} 
Mesmo considerando o aspecto de propaganda destas palavras, é possível deduzir que as informações médicas transmitidas aos participantes da Semana da Tuberculose circularam e foram apropriadas de maneiras diversas pelas pessoas, muitas vezes incorporadas de forma singular por esses indivíduos que tinham costumes que se expressavam inclusive nas formas de tentar combater a doença e manter a saúde (cf. CHARTIER, 2002; THOMPSON, 1998). É preciso considerar a denuncia do doutor Dirceu de Lacerda feita na Revista Médica do Paraná meses antes da Semana de 1937; ele escreveu: "Acreditamos, porém, que a maioria desses doentes [tuberculosos] ande por aí espalhados, fazendo uso de remédios caseiros e até de garrafadas" (Revista Médica do Paraná, maio1936, p.195-197).

Nos anos seguintes o combate à tuberculose foi efetuado em sintonia com a política de saúde do Estado Novo e as atividades educativas para tentar impedir a instalação e propagação da tuberculose foram conjugadas com a divulgação e progressiva utilização de novos recursos preventivos e terapêuticos contra a doença (OLIVEIRA, 2012, p.91-119). Assim, mais que um evento pontual a Semana da Tuberculose de 1937, que culminaria na organização da Liga Paranaense Contra a Tuberculose, foi um acontecimento que, em Curitiba, reuniu e ampliou ações educacionais de combate à moléstia, contando tanto com o consagrado meio de comunicação da época, o jornal (além de folheto, cartazes, faixas e diapositivos), quanto com a grande novidade em comunicação de massa do período, o rádio.

Em 1938, o ano seguinte ao da realização da Semana da Tuberculose, a porcentagem de mortos devido à doença em Curitiba foi de 8,7\% do total dos 1770 óbitos registrados no município, que contava com 122.715 habitantes, porcentagem ainda mais alta do que a registrada em 1937, 8,0\% de mortes por tuberculose; entretanto em 1939 foram 7,2\% os falecimentos por tuberculose, do total de 1805 mortos em Curitiba, que somava 144.999 moradores. O porcentual de mortos pela enfermidade em 1939 foi, portanto, menor que nos dois anos anteriores e o coeficiente de mortes por tuberculose em 100 mil habitantes declinou de 126,3\% em 1938 para 90,3 em 1939 (em 1937 foi 110,3\%) (SOUNIS, 1940, p.39).

No final da década de 1930, Curitiba, a cidade dos "bons ares", continuou no grupo das capitais brasileiras consideradas de "mortalidade moderada" pela tuberculose. Mas, na Semana da Tuberculose o médico José Pereira de Macedo fez uma afirmação que deve ter motivado o questionamento de ouvintes de sua palestra: "pode descer a Zero [o número de tuberculosos] numa aglomeração em que cada indivíduo se disponha a cooperar com a Saúde Publica" (Revista Médica do Paraná, fev.1938, p. 85). Isto seria mesmo possível? Com educação para a saúde, talvez. Esta provavelmente seria a resposta de vários médicos e leigos que participaram da realização da Semana de 1937. 
FONTES

Correio do Paraná, novembro de 1937.

Diário da Tarde, novembro de 1937.

Gazeta do Povo, novembro de 1937.

PARANÁ, Relatório do Interventor do Estado. Snr. Manoel Ribas ao presidente Getúlio Vargas. Exercício de 1932 a 1939. Curitiba, [194-].

Revista Médica do Paraná, fevereiro a junho de 1938.

Revista Médica do Paraná, maio de 1936.

Revista Médica do Paraná, novembro/dezembro de 1937.

SOUNIS, Emilio Leão de Mattos. A marcha de mortalidade pelas doenças infecciosas no município de Curitiba (1905-1939). Tese de Livre Docência da Cadeira de Higiene da Faculdade de Medicina do Paraná. Curitiba, 1940.

REFERÊNCIAS BIBLIOGRÁFICAS

BERTOLLI FILHO, Cláudio. História social da tuberculose e do tuberculoso, 1900-1959. Rio de Janeiro: Ed. Fiocruz, 2001.

BERTUCCI, Liane Maria. A onipresença do medo na influenza de 1918. Varia História. Belo Horizonte, v. 25, n. 42, p.457-475, jul.- dez. 2009.

BERTUCCI, Liane Maria. Saúde pública na capital paranaense: dos 'bons ares' à febre tifoide. Simpósio Nacional de História, XXVI, São Paulo. Anais ... São Paulo: ANPUH-SP, 2011. v.1. p.1-12.

BERTUCCI-MARTINS, Liane Maria. Entre doutores e para leigos: fragmentos do discurso médico na influenza de 1918. História, Ciências, Saúde - Manguinhos. Rio de Janeiro, v. 1, n.1, p. 143-157, jan.-abr. 2005.

CASTRO SANTOS, Luiz Antonio de. FARIA, Lina Rodrigues de. A reforma sanitária no Brasil: ecos da primeira república. Bragança Paulista: Edusf, 2003.

CHARTIER, Roger. A história cultural. 2aㅡ ed. Lisboa: Difel, 2002. 
FAURE, Olivier. O olhar dos médicos. In: CORBIN, Alain; COURTINE, Jean-Jacques; VIGARELLO, Georges (Orgs.). História do corpo. Vol. 2. 2a ed. Petrópolis: Vozes, 2008, p.1355 .

FERNANDES, Lindolfo. O Hospital Oswaldo Cruz e a epidemiologia no Paraná. Curitiba: Casa da Memória da Saúde Pública, [1993?].

FONSECA, Cristina M. Oliveira. Saúde no governo Vargas (1930-1945). Rio de Janeiro: Ed. Fiocruz, 2007.

FONSECA, Cristina M. Oliveira; HOCHMAN, Gilberto. O que há de novo? Políticas de saúde pública e previdência, 1937-1945. In: PANDOLFI, Dulce (Org.). Repensando o Estado Novo. Rio de Janeiro: Ed. FGV, 1999, p. 73-93.

GONÇALVES, Mauro Castilho. Educação, higiene e eugenia no Estado Novo: as palestras de Savino Gasparini transmitidas pela Rádio Tupi (1939-1940). Cadernos de História da Educação. Uberlândia, v.10, n.1, p.151-167, jan.-jun. 2011.

GUERRAND, Roger-Henri. Guerra à tuberculose! In: LE GOFF, Jacques (Apres.) As doenças têm história. Lisboa: Terramar, 1991, p.187-201.

HOCHMAN, Gilberto. Reformas, instituições e políticas de saúde no Brasil (1930-1945). Educar em Revista. Curitiba, n.25, p.127-141, jan.-jun. 2005.

HOERNER JUNIOR, Valério. Rádio Clube paranaense: a pioneira do Paraná. Curitiba: Ed. Champagnat, 2005.

JUK, Beatriz Virmond; FERNANDES, Lindolfo. A tísica no Paraná. Curitiba: Casa da Memória da Saúde Pública, 1992.

KUMMER, Carmen S. da Fonseca. "Não esmorecer para não desmerecer": as práticas médicas sobre a saúde da população rural paranaense na Primeira República, 1916-1930. Mestrado (Dissertação em História), Departamento de História, Universidade Federal do Paraná, 2007.

LIMA, Nísia Trindade; HOCHMAN, Gilberto. Condenado pela raça, absolvido pela medicina: o Brasil descoberto pelo movimento sanitarista da Primeira República. In: MAIO, Marcos Chor; SANTOS, Ricardo Ventura (Orgs.) Raça, ciência e sociedade Rio de Janeiro: Ed. Fiocruz, 1996, p.23-40.

MARQUES, Vera R. Beltrão. A medicalização da raça. Campinas, Ed. Unicamp, 1994.

MOREIRA, Ildeu de Castro; MASSARANI, Luisa; ARANHA, Jayme. Roquette-Pinto e a divulgação científica. In: LIMA, Nísia Trindade; SÁ, Dominichi Miranda de (Orgs.). 
Antropologia Brasiliana: ciência e educação na obra de Edgar Roquette-Pinto. Belo Horizonte: Ed. UFMG, Rio de Janeiro: Ed. Fiocruz, 2008.

MOTA, André. Quem é bom já nasce feito. Rio de Janeiro: DP\&A, 2003.

MOTA, André; MARINHO, Maria Gabriela S.M.C. (Orgs.) Eugenia e história. São Paulo: FFMUSP; UFABC; Casa de Soluções e Editora, 2013.

NASCIMENTO, Dilene Raimundo do. As pestes do século XX: tuberculose e Aids no Brasil, uma história comparada. Rio de Janeiro: Ed. Fiocruz, 2005.

OLIVEIRA, Marinice Sant'Ana de. Em páginas impressas e nas ondas do rádio: ações educativas para combater a tuberculose. Curitiba, 1937-1952. Dissertação (Mestrado em Educação), Setor de Educação, Universidade Federal do Paraná, 2012.

PERROT, M. História dos quartos. São Paulo: Paz e Terra, 2011.

ROSEN, George. Uma história da saúde pública. São Paulo: Hucitec; Ed.Unesp; Rio de Janeiro: Abrasco, 1994.

STEPAN, Nancy L. Eugenia no Brasil, 1917-1940. In: HOCHMAN, Gilberto; ARMUS, Diego (Orgs.) Cuidar, controlar, curar. Rio de Janeiro: Ed. Fiocruz, 2004, p.331-391.

STERN, Iris. As campanhas de prevenção às doenças e sua ação educativa. Dissertação (Mestrado em Educação), Setor de Educação, Universidade Federal do Paraná, 2003.

THOMPSON, Edward P. Costumes em comum. São Paulo: Companhia das Letras, 1998. 